Method We devised a simple tool which enabled staff to state what they wanted to "Stop, Start and Keep" within the services they provided.

Discussion This tool was used in an "away day" style environment, the whole team where engaged in the process and the use of the tool elicited themes from the team in relation to the questions asked, and enabled the team to develop a plan for future developments and discuss key areas of concern.

There was an over arching theme related to maintaining quality which underpinned all such developments and a desire to ensure the quality of care patients received was not adversely affected. The use of the tool acted as a bench mark to where we are now and where we wanted to be, and enables the team to review progress, its impact and celebrate success.

Conclusion The use of this tool enabled the team to feel engaged and contribute to the development of new ideas and ways of working in challenging times. The process is fluid and enables teams the opportunity to revisit and review and address issues and developments.

\section{P63 FIT FOR THE FUTURE.... EMPOWERING AN ORGANISATION THROUGH STRATEGY DELIVERY}

Roslyn Neely. Children's Hospice Association Scotland, Edinburgh, UK

\subsection{6/bmjspcare-2013-000591.85}

Background The organisation has created a visionary strategy to position them as an influential, leading paediatric palliative care provider in Scotland, the UK and beyond. In creating this, there was an opportunity to truly engage with all those involved in the organisation; reflecting visions and hopes for the future through collaboration and consultation. Children, young people and families using the services; trustees, staff and volunteers were consulted through a series of focus groups, externally facilitated to maximise objectivity. This was the starting point for a dynamic ongoing strategic planning process to ensure the organisation is in a strong position to meet the changing needs of babies, children, young people and their families in a changing political and financial landscape.

Method A number of sessions were held to explore what the future might hold for the organisation over the next ten years. This has included exploring the changing needs of the children, young people and families who will use the service; considering new ways of delivering care, skill mix review, the hospice environment, income and expenditure projections, the political landscape, policy and partnership working with statutory and voluntary organisations.

Outcomes Two years on and the resulting strategic plan is delivering measurable outcomes which are positively impacting on the care and support being given to families. The organisation has also influenced the development of a Framework for the Delivery of Palliative Care for Children and Young People (2013). Staff, volunteers and service-users are motivated, guided and empowered by the plan. The plan has raised awareness of the organisation within health and local authority networks, resulting in increased referrals and funding.

\section{P64 FINANCIAL PLANNING FOR UNCERTAINTY}

Alison Ryan, Sheena Keep. Weldmar Hospicecare Trust, Dorchester, United Kingdom

10.1136/bmjspcare-2013-000591.86
Introduction In common with other independent hospices, Weldmar Hospicecare Trust faces considerable uncertainty over the size and nature of future income. This paper describes the financial modelling which allows us to make sound financial plans despite that uncertainty.

Aims To create an understanding of our complex finances so we can focus on the most impactful income generation, control expenditure and use our Balance Sheet strength to create a future where we are no longer dependent on any one source of income.

Approach used

- analysis of expenditure and income steams by type and cost centre (80 + budget lines).

- Application of differential growth/cost pressure assumptions to each line on an Excel model which allows assumptions to be changed producing different results.

Outcomes this command of our finances has allowed us to:

- make budget adjustments in the context of securing long term strength,

- to manage sudden unforeseen changes (such as $90 \%$ failure of legacy income in one year) without making damaging short term cuts,

- to distribute resources to staff via pay in a way which is sustainable and transparent and affordable,

- to invest in income raising possibilities even while running planned $£ 1$ million deficits.

Our model shows that in four years' time we will have generated sufficient surplus to minimise the impact of loss or reduction of NHS income should competitive tendering produce such a result. It provides a clear guide to managers on how service development can, or cannot, be afforded.

Application to hospice practice Hospices have complex and unpredictable income streams - NHS, trading, legacies, donations, investment and relatively fixed costs - largely staffing. Without a long term view, short term reactions to financial hiatus can lead to unnecessary curtailment of services, loss of opportunity and lowered morale. This model minimises those problems.

\section{P65 DEVELOPING A CULTURE OF GOOD LEADERSHIP AND MANAGEMENT}

Lynn Kelly, Stephen Greenhalgh. St Catherine's Hospice, Preston, United Kingdom

10.1136/bmjspcare-2013-000591.87

\section{Background}

- Little interaction between managers across different directorates

- No sense of 'team' amongst managers

- Lack of consistent approach and varying degrees of management experience

Aim

- Set standard for leadership \& management amongst middle managers

- Raise confidence of managers in dealing with staff performance

- Develop team working across departments

- Enable managers to contribute to and deliver the Hospice 5 year plan

Approach Used 
- Researched suitable providers, developed partnership with Lancashire Teaching Hospitals NHS Foundation Trust Leadership and Organisational Development Team

- Training Needs Analysis - rated confidence across different leadership and management areas and then prioritised for development.

- Key components:
- 7.5 days of group training
- Leadership \& Management Situational Judge- ment Test
- Self-assessment against NHS Leadership Framework
- 1-2-1 with advisor
- Group project work / presentation
- Impact evaluation (due June 2013)
- ILM Level 5 qualification

\section{Outcomes}

- 'The difference in the first Management Team meeting following the course was tangible and exciting. Colleagues were more confident, open and prepared to actively challenge and contribute. I came away greatly encouraged by the credible difference which entirely justifies the investment that we made into establishing an Education Team that can sharpen our business effectiveness at every level just at a time when we need it most!' - Stephen Greenhalgh, CEO

- In my directorate, confidence in their own ability springs to mind, they have been committed to the appraisal scheme and cascading from the business plan to performance plans" - Lorraine Charlesworth, Director of Income Generation

- "My attendance on the Management course assisted me to reflect on my Management style and enabled me to increase delegation to my staff. It also improved my working relationship with my line Manager and other Managers on the programme." - Cheryl Scott, FamilySupportTeam Manager

- "One of the most practically useful courses I've ever been on - combined theoretical and applied knowledge made the content easily transferable to the workplace. I have already implemented many changes within my team." Katie Russell-Paddison, HeadofAdmin

- Key Operating Principles

- Developing leadership for a new era

- Developing the hospice workforce

\section{P66 DEVELOPING AND SUPPORTING MANAGEMENT AND LEADERSHIP WITHIN A HOSPICE}

${ }^{1}$ Joanna Kennedy, ${ }^{2}$ Pam McClinton, 'Joette Thomas, ${ }^{1}$ Duncan Wallace. ${ }^{1}$ Animate, Edinburgh, United Kingdom, ${ }^{2}$ North London Hospice, London

\subsection{6/bmjspcare-2013-000591.88}

This abstract outlines the innovative way the North London Hospice sought to improve the effectiveness of all of its leadership and management practice using values as a bedrock.

From 2011 - 2013, the Animate team developed and ran a management development programme for all 31 managers from across. The purpose of the programme was to provide an integrated learning opportunity that strengthened the skills, understanding and effectiveness of the management of the Hospice

The design of the programme paid attention to the environment in which the staff worked. A wide variety of issues were raised for them which had implications for creating a system of management and leadership which truly integrates core values throughout the organisation and into all aspects of care.

The programme enabled participants to analyse their own experience using a collection of theories and frameworks, which deepened their understanding of their role. It addressed the particular management challenges of working in hospice setting where staff are mostly highly motivated, passionate, inclined to work very hard and exposed to a high degree of emotion in the course of their day. It included both opportunities to reflect through action learning and focused action planning.

Six months after the end of the programme the Executive Team were seeing the impact on management practice. They were noticing managers broadening and adapting their leadership styles to suit different situations. They also observed tools and frameworks being successfully used to analyse difficult problems and plan new initiatives. They were seeing managers being more confident and clearer about what their role involved. The greatest impact was on opening up and deepening learning across departments, disciplines and teams.

Animate has now teamed up with the North London Hospice to design and deliver programmes in other hospices tailoring the content to meet particular contexts.

\section{P67 USING A SERVICE EVALUATION TO DRIVE CHANGE AND IMPROVE QUALITY}

Peter Newman, Jane White, Martin Plowman. Dreams Come True, Liphook, UK

\subsection{6/bmjspcare-2013-000591.89}

Introduction Dreams Come True is a national charity providing dreams for children age 2-21 with life-threatening and life-limiting conditions. As part of our overall commitment in our 25 th year to improving the quality of our dream delivery service, we have embarked on a programme of service improvement. Voluntary organisations have a key role to play in palliative care pathways and it is important that the sector is a serious partner in the drive to improve services.

Aim The starting point was an independent service evaluation designed to evaluate the views of all our stakeholders: the internal team; the key professionals who refer to our service; and most importantly the families that we serve.

Methods The study methodology used a combination of nominal group technique for parents and staff team and email survey among key referring informants.

Results This paper will focus on the lessons learned by the charity in undertaking the study and will describe the process of internal review, re-evaluation and implementation of change that has now been actioned. Such changes include ways in which we will be involving families and communications practices with professionals as well as a re-evaluation of our services to young adults in transition.

Conclusion We will describe the ongoing methods by which we will monitor the impact of those changes which we hope will achieve quality improvements to all stakeholders in our organisation. It will be of interest to other voluntary organisations supporting palliative care services nationwide especially those considering undertaking a service evaluation. It will also be of interest to children's hospitals and hospices with an interest in the professionalism and effectiveness of the service delivery of such voluntary organisations. 